\title{
Adhesion of Silica Particles on Thin Polymer Films Model of Flax Cell Wall
}

\author{
Samia Mahouche-Chergui1* ${ }^{*}$, Yves Grohens1 ${ }^{1}$ Eric Balnois¹, Bénédicte Lebeau², \\ Yves Scudeller ${ }^{3}$ \\ ${ }^{1}$ Laboratory of Materials Engineering of Brittany, University of South Britany, Morbihan, France \\ ${ }^{2}$ Mulhouse Materials Science Institute, University of Haute Alsace, Mulhouse, France \\ ${ }^{3}$ LGMPA, University of Nantes-Polytechnic School, France \\ Email: * $\underline{\text { mahouche-chergui@icmpe.cnrs.fr }}$
}

Received 10 September 2014; revised 11 October 2014; accepted 27 October 2014

Copyright (C) 2014 by authors and Scientific Research Publishing Inc.

This work is licensed under the Creative Commons Attribution International License (CC BY).

http://creativecommons.org/licenses/by/4.0/

(c) (i) Open Access

\section{Abstract}

The present work is focused on better understanding of the interfacial interactions of SBA-15 mesoporous silica particles with flax fibers. In order to overcome the inherent complexity of flax fiber surface composition we have prepared model polysaccharide surfaces representing the main component of the flax fibers, e.g. cellulose, polygalacturonic acid (PGUA), and xyloglucan (XG) with thicknesses of about $200 \mathrm{~nm}, 100 \mathrm{~nm}$, and $110 \mathrm{~nm}$, respectively. The $\xi$-potential measurements of both silica and polysaccharides were performed in aqueous solutions as a function of $\mathrm{pH}$ and ionic strength. $\xi$-potential, AFM and SEM results supported the important role of electrostatic interactions in the silica adsorption on polysaccharide surfaces, since silica adsorption increased remarkably with ionic strength. The adsorption density of the SBA-15 onto the various polysaccharides was Cellulose $>$ PGUA $>\mathrm{XG}$, and the maximum was observed at $\mathbf{p H}=4$. Urea used as hydrogen bonds breaker reduced significantly the adsorption of SBA-15 on the polysaccharide surfaces, which highlighted the significant contribution of hydrogen bonding in the adsorption process. It was observed that most adsorbed SBA-15 particles were resistant to ultrasonic washing, which revealed their strong irreversible adsorption. Finally, direct adsorption experiments on both raw and treated real flax fibers yielded results consistent with those of model surfaces showing the important role of the surface fibers treatments on the improvement of the interfacial adhesion of the silica particles with flax fibers. The remarkable affinity of the SBA-15 particles with treated flax fibers is encouraging to design superinsulators composites with tuneable mechanical performances.

\section{Keywords}

Adhesion, SBA-15 Mesoporous Silica, Polysaccharides, Model Surfaces, Flax Fibers

\footnotetext{
${ }^{*}$ Corresponding author.
}

How to cite this paper: Mahouche-Chergui, S., Grohens, Y., Balnois, E., Lebeau, B. and Scudeller, Y. (2014) Adhesion of Silica Particles on Thin Polymer Films Model of Flax Cell Wall. Materials Sciences and Applications, 5, 953-965. 


\section{Introduction}

Developments of innovative efficient materials presenting high thermal insulation performances have recently attracted a great deal of interest because of their remarkable potential in building sector. In this context, a variety of inorganic materials have been used in designing of new materials with excellent physical and chemical structures due to their very high porosity, nano-scale pore sizes and lightweight. Such promising kinds of materials are called aerogels well-known as superinsulators. Indeed these systems yield a significant decrease of solid and gaseous thermal conductivity due to air confinement effect [1]-[3]. The characteristic of small solid thermal conductivity is the result of the high porosity of the aerogels structure, while the low gaseous thermal conductivity can be explained by the Knudsen effect, describing the gaseous conduction in a porous media as function of the air pressure and the characteristic pore size [4] [5].

Most of these inorganic superinsulating aerogels deal with silica materials that consist of a cross-linked internal structure of silicon oxide chains with a large number of air-filled pores. However, the main disadvantage of these materials is nevertheless, their low mechanical strength resulting from their low mass density. The silica aerogels fragility restricts considerably their use in conventional industrial applications. In order to improve the mechanical resistance of these ultraporous structures, extensive efforts are being made to develop organic-based aerogels. Among the various proposed materials, one can cite resorcinol/formaldehyde aerogels [6], and polyurethane, polyisocyanurate aerogels [7] [8]. Another alternative way for pure silica aerogels is their coupling with a more mechanical resistant material in order to elaborate strong and flexible aerogel-composites [9].

Considering the increasing environmental awareness, the biggest challenge of thermal superinsulator materials is not only their improving energetic behavior, but also their environmentally-friendly property which is of great interest from both economic and ecologic viewpoints [9]. Indeed, in the search to substitute traditional insulating materials with ecologically sourced alternatives, many attempts and efforts have been made to use biodegradable, recyclable and renewable materials. Vegetable fibers have been considered as one of the most promising available natural materials candidates for the development of eco-friendly building insulators due to their low density, porous structure, low cost, renewability and their intrinsic mechanical properties [10]. Such fibers have complex microstructure; they are composed by crystalline cellulose polysaccharide organized on several fibrils of around $10 \mathrm{~nm}$ diameter embedded in an amorphous matrix mainly composed of pectins and hemicelluloses. The cellulose fibrils constitute the layers of both primary and secondary cell walls [11] [12]; their unique structure, molecular organization and high crystallinity offer high strength to the flax fibers [13] [14]. The lumen cavity presented inside the secondary cell confers to the fibers a porous structure that makes them suitable for classical thermal insulation. Indeed, Kymäläinen and Sjöberg [15] have reported the suitability of bast fibers of flax in building thermal insulation; however, they have noticed their negative effects on indoor air quality if they are used alone. In order to overcome this risk, authors have proposed to use the bast fibers of flax with additives. Similarly, Kozlowski et al. [16] have demonstrated that flax fibers can be used as filling and facing insulation materials. Still under debate, some life-cycle analyses show that these natural raw fibers ensure more ecological characters than glass wool conventionally used in houses thermal insulation. More recently, El Hajj and co-workers [17] have reported that production of efficient thermal insulating materials using flax-tows need their association with more mechanical resistance-materials. Innerlohinger et al. [18] have described for the first time an aerogel material entirely prepared from renewable resource using cellulose-the main component of the vegetable fibers. They conclude that the physical and chemical properties of the as-prepared cellulose aerogel permit its application in the field of thermal insulation.

In this context, we aimed at designing new porous material based on flax fibers coated with SBA-15 mesoporous silica particles. The interest of SBA-15 lies in its high specific surface area, ordered pore systems, and uniform and nano-scale pore diameters. In addition to the physico-chemical interest, the particles are synthesized via the well-known sol-gel method classified as soft chemistry process, which offers great potential in eco-friendly insulation applications [19]. Due to their mechanical, thermal, and optical properties of the silica/cellulose composites, they are emerging as promising materials in different fields especially papermaking applications. For improving the silica particles dispersion and increasing their attractive forces with cellulose, Holmberg et al. [20] have prepared the composite in highly charged cationic polyelectrolyte, while some other authors have proposed the sol-gel process [21] [22], as well as cellulose chemical functionalization [23].

Therefore, understanding the effects of fibers characteristics and their interfacial interactions with the silica particles is essential to the improvement and optimization of both the mechanical properties and the thermal insulating performances of the fiber-silica composite. However, the very complex composition and heterogeneity 
of the flax fibers, as reported above, make difficult the understanding of the adsorption mechanisms on real fiber. In order to make simplify the system we have represented the fiber by model surfaces of its main polysaccharides, as recently reported by our group in the study of the adhesion of PLA with flax fibers [24]. Smooth cellulose, xyloglucan and pectin surfaces were prepared via spin-coating method, and used separately to study their affinity with the SBA-15 particles in aqueous media. The morphology of the prepared polysaccharide surfaces was analyzed by atomic force microscopy, and their wettability with water contact angle measurements. Apart from the micrometer-scale of the SBA-15 visualized by SEM, we have also used Stöber colloidal silica of nanometer-scale to characterize the obtained surfaces by AFM microscopy in tapping mode. This comparison is expected to reinforce our understanding of the interactions between the mineral charges with the polysaccharide model surfaces. The surface charge of the different polysaccharides and the silica particles was determined using zeta potential measurements. Then we have studied and compared the adsorption capacity of SBA-15 on the model surfaces varying preparation conditions, such as the initial $\mathrm{pH}$ solution and the ionic strength, followed by using urea chelating agent in order to evaluate the hydrogen bonding interactions between hydroxyl groups of SBA-15 and polysaccharide surfaces. Finally, we have investigated the effect of the flax fiber wall treatments on the interface SBA-15/flax fibers using scanning electron microscopy.

\section{Materials and Methods}

\subsection{Materials}

Microcristalline cellulose with an average size of $20 \mu \mathrm{m}$ (Cellulose, Aldrich), polygalacturonic acid extracted from orange (PGUA, Sigma-Aldrich), it's the major component of pectin, Xyloglucan from tamarind seed (XG, Megazyme), tetraethyl orthosilicate (TEOS, 98\%, Aldrich), triblock copolymer P123 (PEO20PPO70PEO20), sodium chloride ( $\mathrm{NaCl}$, Sigma-Aldrich), calcium chloride $\left(\mathrm{CaCl}_{2}\right.$, Sigma-Aldrich), urea (Sigma-Aldrich), ammonia (28\%, Acros), absolute ethanol (Fisher Scientific), sodium hydroxide (NaOH, 99\%, Sigma-Aldrich), hydrochloric acid ( $\mathrm{HCl}, 37 \mathrm{wt} \%$, Sigma-Aldrich) were used as received without further purification. The lithium chloride ( $\mathrm{LiCl}$, Aldrich) was dried at $200^{\circ} \mathrm{C}$ for 1 day, and the $N, N$ - dimethylacetamide (DMAc, Sigma) was freshly dried at $110^{\circ} \mathrm{C}$ prior to use.

The used flax fibers (Marylin variety) are grown in Neubourg (France) in 2009. 18 M $\Omega$ Milli-Q (Millipore) water was used in the preparation of all the aqueous solutions.

The amount of silica adsorbed amount is determined using ImageJ software (NIH USA).

\subsection{Synthesis of Stöber Silica Nanoparticles}

Spherical silica nanoparticles were prepared using Stöber sol-gel procedure. A mixture of $14 \mathrm{~mL}$ of TEOS and $56 \mathrm{~mL}$ of ethanol was added to a solution of $144 \mathrm{~mL}$ of ethanol, $18 \mathrm{~mL}$ of water and $7 \mathrm{~mL}$ of ammonia, and the mixture was stirred at room temperature under nitrogen atmosphere for $2 \mathrm{~h}$. The resulting nanoparticles were thoroughly washed with ethanol via three repeated cycles of centrifugation/dispersion, and then dried in oven at $110^{\circ} \mathrm{C}$ overnight.

\subsection{Synthesis of SBA-15 Mesoporous Silica}

SBA-15 hexagonal mesoporous silica particles were prepared using non ionic surfactant, Pluronic P123 as structured agent; typically $4 \mathrm{~g}$ of P123 was dissolved in a mixture of $19.5 \mathrm{ml} \mathrm{HCl} 12 \mathrm{M}$ and $127 \mathrm{ml}$ of distilled water. After $3 \mathrm{~h}$ of vigorous stirring at $40^{\circ} \mathrm{C}, 8.62 \mathrm{~g}$ of TEOS were added under stirring, and after $5 \mathrm{~min}$ of TEOS addition the stirring was stopped and the solution was maintained at $40^{\circ} \mathrm{C}$ for $2 \mathrm{~h}$. Then the product was filtered and thoroughly washed with distilled water and then dried in oven at $70^{\circ} \mathrm{C}$ for $48 \mathrm{~h}$. In order to liberate the porosity, by removing the template, the as prepared particles were calcinated in a muffle furnace at $500^{\circ} \mathrm{C}$ for $4 \mathrm{~h}$.

\subsection{Preparation of Polysaccharide Model Surfaces}

The model surfaces preparation is a two-step process, the dissolution of the polysaccharides and then deposition of these solutions on freshly cleaved mica surfaces cut to $1 \mathrm{~cm}$ squares, as reported previously by Raj et al. [24]. Briefly, the XG and PGUA solutions were prepared at a concentration of $10 \mathrm{~g} \cdot \mathrm{L}^{-1}$ by dissolving in Milli-Q water and in an acetate buffer solution of $\mathrm{pH} 4.5$, respectively. The $0.5 \mathrm{wt} \%$ cellulose solution was prepared by dissolving microcrystalline cellulose in a solution of $9 \% \mathrm{LiCl}$ in DMAc. A drop of the filtred $(0.1 \mu \mathrm{m}$ diameter $)$ 
biopolymer solution was deposited on a mica surface and spin-coated for $1 \mathrm{~min}$, at $2500 \mathrm{rpm}$ in the case of XG and PGUA, and at $3000 \mathrm{rpm}$ for cellulose. The obtained XG and PGUA thin films were subsequently dried at $50^{\circ} \mathrm{C}$ under vacuum for 4 hours, and the cellulose thin film was previously washed in Milli-Q water in order to remove the adsorbed $\mathrm{LiCl}$, and then dried at $160^{\circ} \mathrm{C}$ under vacuum for $10 \mathrm{~min}$.

\subsection{Adsorption of Silica Particles on Model Surfaces}

The cellulose, XG, and PGUA model surfaces were incubated separately on $10 \mathrm{~mL}$ of $3 \mathrm{~g} \cdot \mathrm{L}^{-1}$ silica suspension with agitation using a magnetic stirrer during $2 \mathrm{~h}$ at room temperature. The suspensions were adjusted to the desired $\mathrm{pH}$ ranging from 2 to 8 , by adding aliquots of $\mathrm{HNO}_{3}(1 \mathrm{M})$ or $\mathrm{NaOH}(1 \mathrm{M})$ at the beginning of the experiment. Afterward surfaces were washed with Milli-Q water under sonication, and dried under air. In order to study the effect of ionic strength on silica particles adsorption, experiments were conducted in presence of $\mathrm{CaCl}_{2}$ at four different concentrations varying from $5 \times 10^{-3}$ to $5 \times 10^{-2} \mathrm{M}$.

\subsection{Flax Fibers Treatments and SBA-15 Adsorption on the Fibers}

The flax fibers have been treated with different solvents, as soxhlet, water and sodium hydroxide. All these treatments procedure were described in detail in literature [25] [26]. Briefly, the soxhlet treatment was achieved by subjecting the fibers to toluene/ethanol $[75 / 25(\mathrm{v} / \mathrm{v})]$ mixture extraction for $24 \mathrm{~h}$. The cleaned fibers were then washed for several times with Milli-Q water and then dried in an oven under vacuum at $80^{\circ} \mathrm{C}$ for $5 \mathrm{~h}$. Water and $\mathrm{NaOH}$ treatments were performed by soaking $1 \mathrm{~g}$ of soxhlet-pretreated fibers in $100 \mathrm{ml}$ of water or in $5 \mathrm{wt} \%$ of $\mathrm{NaOH}$ solutions for $72 \mathrm{~h}$ and $20 \mathrm{~min}$ at $23^{\circ} \mathrm{C}$, respectively. Afterwards, the $\mathrm{NaOH}$-treated fibers were washed for several times with Milli-Q water, neutralized with a few drops of acetic acid solution, then washed again with water and finally dried in an oven under vacuum at $80^{\circ} \mathrm{C}$ for $5 \mathrm{~h}$. The experiments of adsorption of SBA- 15 on the flax fibers were performed by introducing $0.05 \mathrm{~g}$ of untreated, soxhlet, water, and $\mathrm{NaOH}$ treated fibers in $20 \mathrm{ml}$ of $3 \mathrm{~g} \cdot \mathrm{L}^{-1}$ suspension of SBA-15 at $\mathrm{pH} 4$ for $2 \mathrm{~h}$. The loaded-fibers were then washed for with Milli-Q water under sonication and then dried in an oven under vacuum at $80^{\circ} \mathrm{C}$ for $5 \mathrm{~h}$.

\subsection{Biopolymers Thin Films and Biocomposites Characterization}

\subsubsection{Atomic Force Microscopy (AFM)}

Morphology, roughness and thickness of polysaccharide model surfaces, and their surface adsorption of Stöber silica nanoparticles were accomplished by tapping mode AFM under ambient conditions $\left(23^{\circ} \mathrm{C}\right.$ and $\left.56 \% \mathrm{RH}\right)$ using a Nanoscope IIIa multimode scanning probe microscope from Veeco, USA.

\subsubsection{Scanning Electronic Microscopy (SEM)}

Adsorption and dispersion of SBA-15 nanoparticles on the different polysaccharide surfaces were investigated using a Jeol JSM 6460LV scanning electron microscope. All the samples were sputter-coated with gold before analysis.

\subsubsection{Contact Angle Measurements}

The room temperature static contact angle of water on the different polysaccharide films was determined with a Digidrop GBX. The contact angles were measured after $20 \mathrm{~ms}$ water droplet deposition.

\subsubsection{Zeta Potential Measurements ( $\xi$-Potential)}

The zeta potentials measurements of cellulose, PGUA, XG, and silica nanoparticles at pH 2 - 8 rang were determined by dynamic light scattering (DLS) at $25^{\circ} \mathrm{C}$ using a Malvern Zetasizer Nano ZS instrument. The solutions were prepared dissolving or dispersing the polysaccharides and the silica particles in Milli-Q water at a concentration of $1 \mathrm{~g} / \mathrm{L}$, using ultrasonic bath during $2 \mathrm{~h}$, then magnetic stirrer during $15 \mathrm{~h}$. Each data value is an average of three measurements.

\section{Results and Discussion}

\subsection{Structure and Surface Charge of the Biopolymers and Silica Particles}

Investigation of the relations between electric charges is essential for understanding the mechanism of silica par- 
ticles interaction with flax fiber biopolymers. The surface electric charge can be assessed by zeta potential, known as a measurable parameter related to the charge and electric double layer of surfaces in aqueous solutions. The zeta potential can also be described as the electrical potential at a hypothetical "slip plane" adjacent to a charged surface [27]. This ionic double layer results from the solvation of charged particle. Therefore, zeta potential parameter is based on the charge displacement in the electric double layer caused by an external force shifting the liquid phase tangentially against the solid [28]. The electrophoretic mobilities were converted to zeta potential using the Smoluchowski-Helmhotz equation:

$$
\xi=\left(\varepsilon \cdot \mu_{E}\right) / \eta
$$

where $\xi$ is the zeta potential $(\mathrm{mV}), \varepsilon, \mu_{E}$ and $\eta$ are the dielectric constant of the solution, the electrophoretic mobility and viscosity, respectively. $\mu_{E}=V_{E} / E$, with $V_{E}$ is the electrophoretic rate $\left(\mathrm{s}^{-1}\right)$ and $E$ represents the electric field $\left(\mathrm{V} \cdot \mathrm{m}^{-1}\right)$.

Figure 1 shows the relation between the zeta potential and the $\mathrm{pH}$ of the silica particles in aqueous media. It can be observed that all the compounds have no point of zero charge; they exhibit negative zeta potential in the studied $\mathrm{pH}$ range from 2 to 8 , except $\mathrm{Stöber}_{\mathrm{SiO}_{2}}$, which shows an isoelectric point located around $\mathrm{pH}$ 2.8. This Figure shows that $\xi$-potential is significantly influenced by the $\mathrm{pH}$ of the silica dispersions.

It is noteworthy that the zeta potential is not only used to determine the surface charge of colloidal systems especially silica particles, but can be extended to the macromolecules materials [29]. However huge differences between the two systems rely on the complexity of the polymer that make the signification of the net surface charge density in polymers more puzzling. In particular, polysaccharides chains adopt different chain configurations that result generally from polymer-media interactions. In aqueous solution, polysaccharides such as xyloglucan, can be completely water-soluble, partially water soluble like PGUA, or insoluble like cellulose. Such differences can largely be affected by solution $\mathrm{pH}$ and ionic strength, and therefore play an important role on chains conformations. The chains conformations can remarkably change the surface character of the polysaccharides, thus their zeta potential value as reported previously by Obaidat et al. [30] in the case of chitosan, and by Carneiro-da-Cunhaa et al. [31] [32] for various other polysaccharides. As stated by Bellmann et al. [33] the change in the zeta potential value of natural polymers is not only the consequence of their surface chemical composition like presence or absence of functional groups, but also by their swelling behavior (e.g. water uptake). According to the literature [34] [35], the absolute values of zeta potential of natural fibers and nanofibrils decrease with moisture content. The authors explained their observations by the shift of the slip plane with swelling of the fibers in the used solvent.

The surface electric charge on aqueous solutions of the studied polysaccharides (Figure 2) is attributed to the presence of multiple free hydroxyl groups (cellulose, xyloglucan) and carboxylic acid functions (polygacturonic acid). These groups are known to be easily dissociated with varying the solution $\mathrm{pH}$. On the other hand, the abundance of these functional groups yields polysaccharides association via hydrogen bonding resulting on the possibility of macromolecules aggregation. This associative behavior explains the low zeta potential values

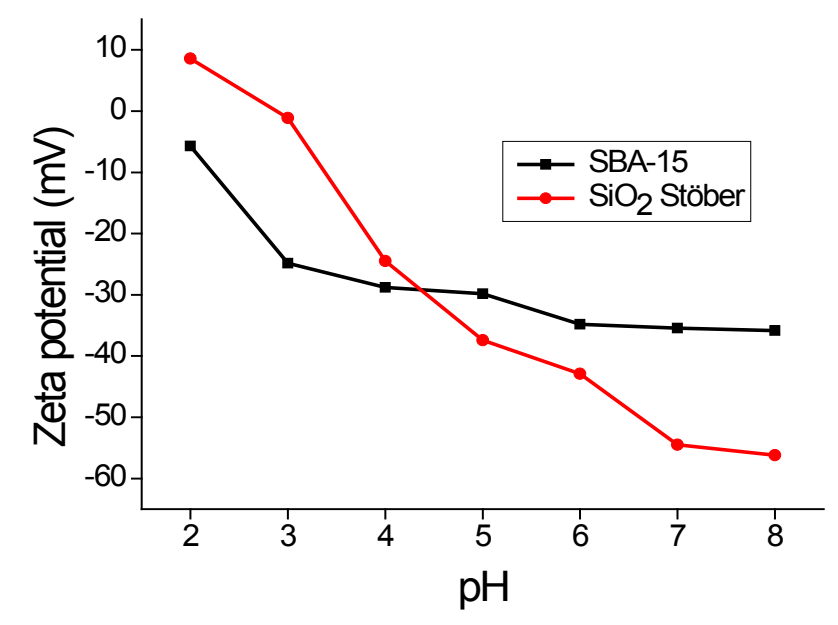

Figure 1. Zeta potential of $\mathrm{SiO}_{2}$ Stöber and SBA-15. 


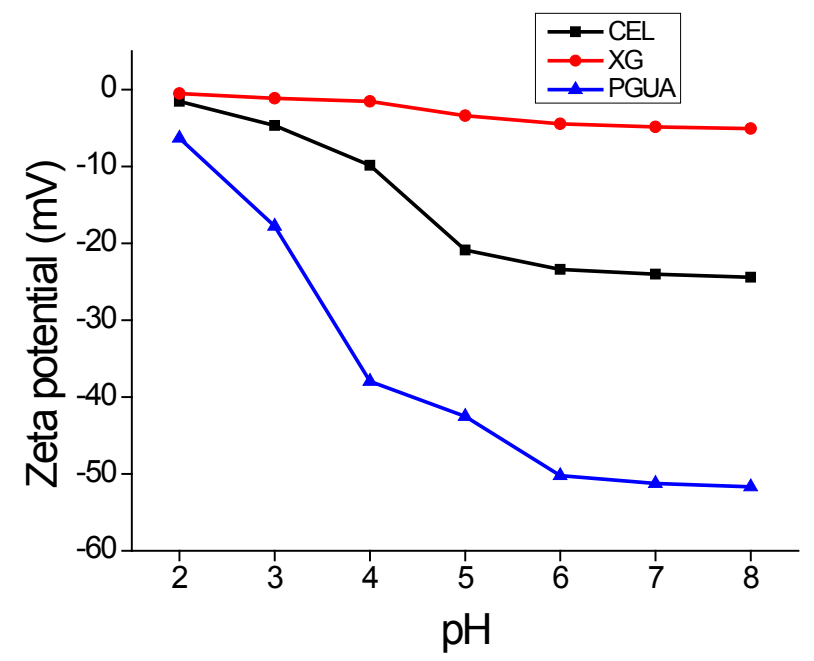

Figure 2. Zeta potential of cellulose, xyloglucan and PGUA versus $\mathrm{pH}$.

obtained at high acidic $\mathrm{pH}$. It can also be observed that the surface charge became strongly negative with increasing $\mathrm{pH}$, except for $\mathrm{XG}$ for which, the zeta potential was only slightly modified versus $\mathrm{pH}$. The values obtained for cellulose and PGUA indicate that the surface of the materials present a sufficient number of anionic charges $(\mid \xi$-potential $\mid>30 \mathrm{mV}$ ) due to the dissociation of the hydroxyl or carboxylic acid functional groups present in a high amount on the various molecules as described previously. We can also notice the pronounced plateau values observed for all the series of materials, which can correspond to the stabilization of their surface charge in the neutral-alkaline range. The low absolute value of the zeta potentials of XG, less than $15 \mathrm{mV}$, may be attributed to its neutral surface [36], while its small dependence on $\mathrm{pH}$ can be explained by the low mobility of the proton of its hydroxyl groups and therefore their poor dissociation.

\subsection{Surface Morphology and Wettability of Polysaccharide Films}

AFM surface morphology and height profiles images (Figure 3) show that the PGUA and XG films are highly smooth and homogeneous, with an RMS roughness estimated on a scan size of $5 \mu \mathrm{m}^{2}$ averaged $0.7 \mathrm{~nm}$ for both the films. However, the cellulose film was slightly rougher, with an RMS of about $4 \mathrm{~nm}$. Cellulose layers can be considered as a rather compact nanoporous network. TM-AFM was also employed to determine the films thicknesses by scanning the scratched surfaces and measuring the difference in height between the top polysaccharide films and the mica surface. The obtained thicknesses were found to be of the order of magnitude of $200 \mathrm{~nm}, 100$ $\mathrm{nm}$ and $110 \mathrm{~nm}$ for cellulose, PGUA and XG, respectively. These AFM results confirm that the prepared thin films can be used as model polysaccharide surfaces representing the real polymers of the flax fiber to study their adhesion with silica particles in aqueous solutions. The contact angles of the prepared films were found to be $40^{\circ}, 35^{\circ}$, and $25^{\circ}$ indicating their hydrophilic nature, owing to the strong interaction of the $\mathrm{OH}$ groups of the cellulose, XG and PGUA, respectively, with water molecules.

\subsection{Effect of $\mathrm{pH}$ and the Nature of the Polysaccharide on Silica Adsorption}

The properties of polysaccharide surfaces and silica particles are strongly $\mathrm{pH}$-dependent due to the dissociation of OH-groups of hydroxyl, carboxylic acid, and silanol functions of cellulose and XG, PGUA, and $\mathrm{SiO}_{2}$, respectively. Several works reported the $\mathrm{pH}$ of isoelectric point at $25^{\circ} \mathrm{C}$ of silica that ranges from 1.7 to 3.5 and that is close to 3 for most of the polysaccharides [37] [38].

The effect of $\mathrm{pH}$ on the adsorption of silica nanoparticles onto the polysaccharide thin films was evaluated at $\mathrm{pH}$ ranging from 2 to about 8 (lower and higher $\mathrm{pH}$ values were not studied because of the possibility of dissolution of silica particles) via AFM and SEM characterizations (Figure 4). It is worth noting that in this range of $\mathrm{pH}$, dynamic light scattering has evidenced that the particles are stable and homogenous in aqueous solution. ImageJ software (NIH, USA) was used to evaluate the adsorbed silica particles amount from SEM analyses and 

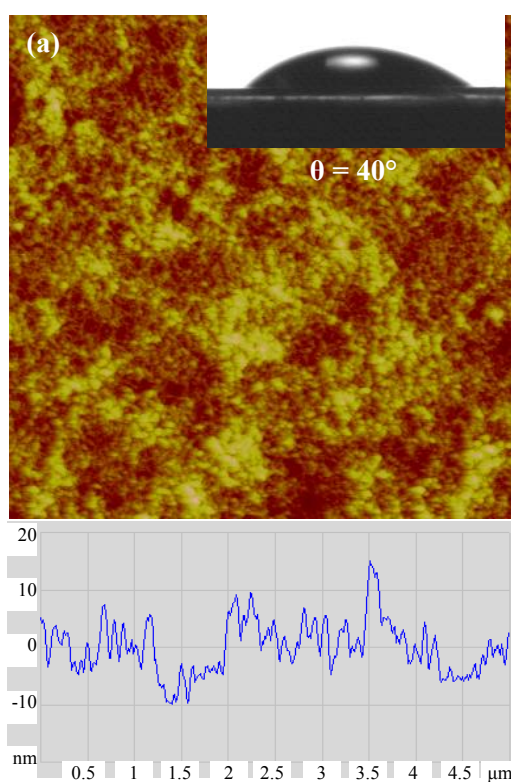
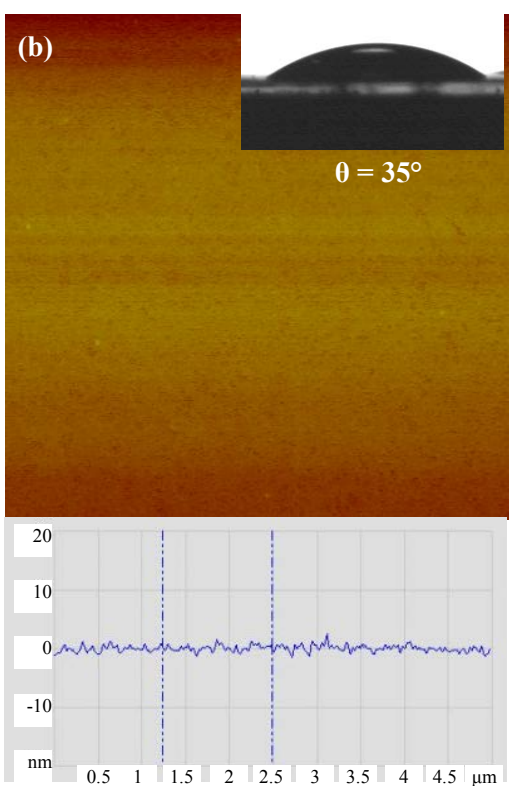
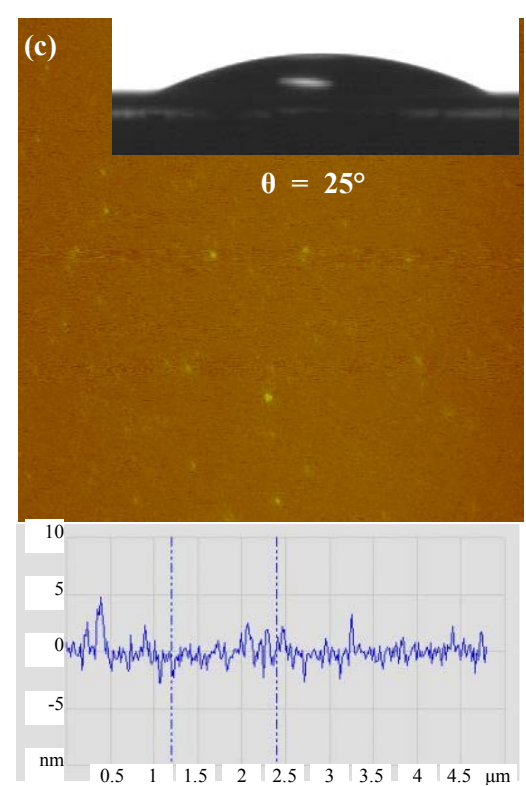

Figure 3. AFM surface topographic images on $5 \mu \mathrm{m} \times 5 \mu \mathrm{m}$ scales, cross sections of the various deposited films (a) cellulose, (b) xyloglucan) and (c) polygalacturonic acid. Inset photos of water droplets on the films.

Cellulose

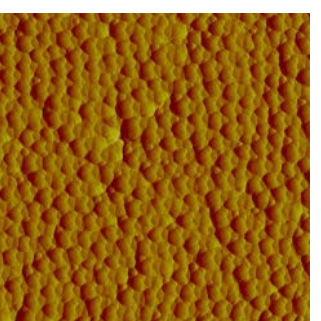

$\mathrm{pH}=4$

$\mathrm{pH}=2$

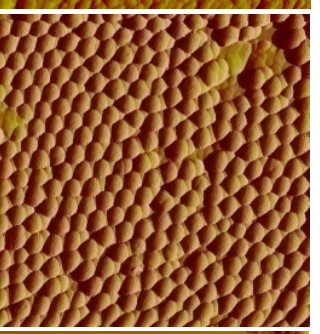

$\mathrm{pH}=7$

$\mathrm{pH}=8$
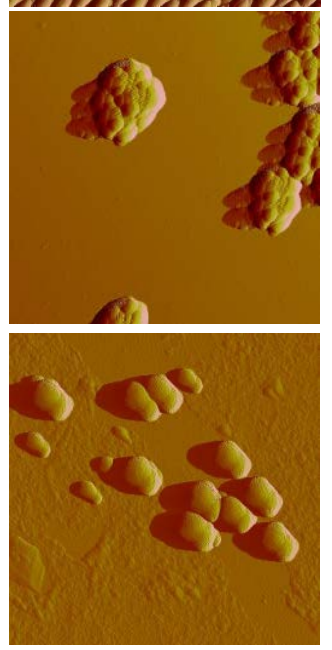

PGUA
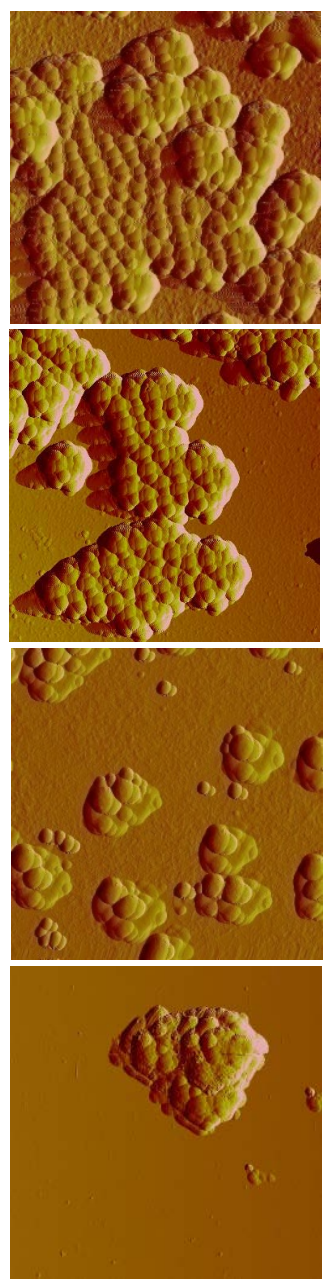

XG
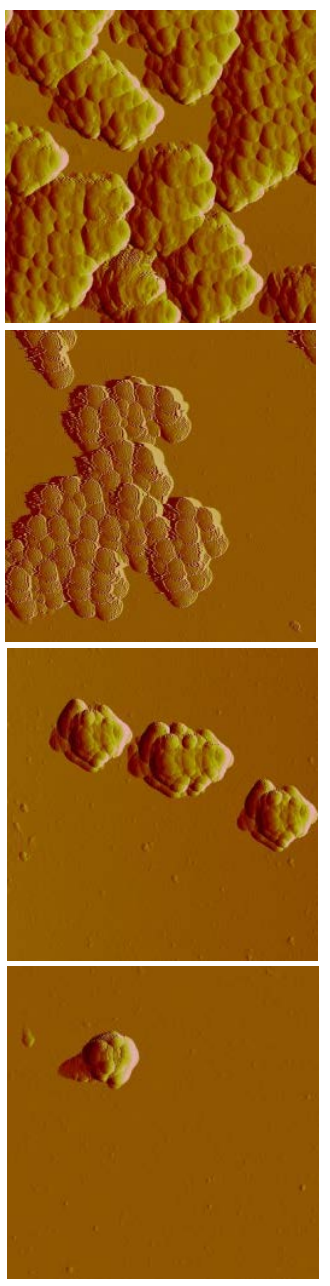


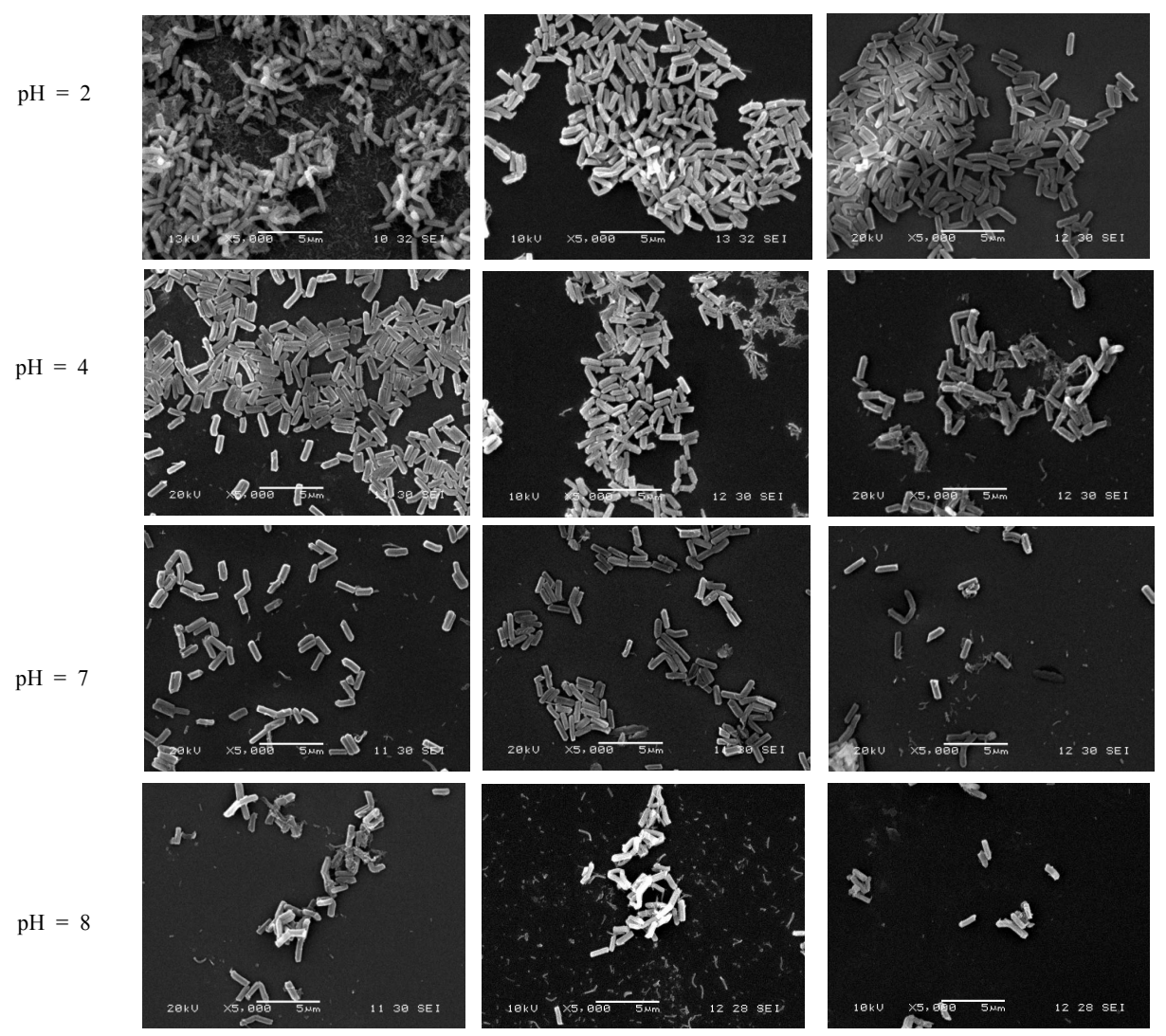

Figure 4. AFM surface topographic images of the $\mathrm{SiO}_{2}$ (top) and SEM micrographs of SBA-15 (down) adsorbed on cellulose, PGUA and XG films at $\mathrm{pH} 2,4,7$ and 8.

the obtained results are given as adsorbed quantity per $5 \mu \mathrm{m}^{2}$ of polysaccharide surface versus $\mathrm{pH}$ as illustrated in Figure 5. It is assumed for that image treatment that silica particles are adsorbed in $2 \mathrm{D}$ in monolayers equivalent.

It clearly appears that $\mathrm{pH}$ plays an important role in immobilization of SBA-15, due to the variation of its surface chemistry with $\mathrm{pH}$. As can be observed from both SEM and AFM results, cellulose films exhibited higher ability to bind and to disperse homogeneously on the surface the silica particles than PGUA and XG films, respectively, at all $\mathrm{pH}$ values (Figure 4). The main reason for this marked difference of silica adsorption between the various polysaccharides (cellulose $>$ PGUA $>$ XG) would be due to the difference of their surface chemistry. The similar negative charges of both silica particles and cellulose biopolymer measured by zeta potential measurements brings the conclusion that the adsorption is not only due to the electrostatic interactions but also to van der Waals interactions and hydrogen bonding. Indeed, the strong material affinity at acidic pH partially originate from the poor electrostatic repulsion and the high hydrogen bonding between the high amount of accessible silanol groups of silica particles and hydroxyl functions of cellulose. In addition, as stated by Ribitsch et al. [36], the high negative zeta potential values indicate strong degree of swelling of polysaccharides. Such swelling might enhance the flexibility of the polymer chains and therefore the accessibility of interacting sites to the silica particles. Similarly, the high interaction between silica and PGUA and XG in the acidic conditions can be attributed to the van der Waals contribution whereas the weak adhesion of the particles toward cellulose and PGUA films at basic $\mathrm{pH}$ regions can be related to the strong electrostatic repulsions when all the species are highly negatively charged. It can be noticed that at $\mathrm{pH} 2$, the poorly charged silica particles have a tendency to aggregate due both to van der Waals attraction and association through hydrogen bonding, showing a large surfaces covering of all the polysaccharide films. The explanation comes from the neutral charge of the surface of the silica particles at this $\mathrm{pH}$, closer to their isoelectric point. One can see a strong decreasing of the adsorbed amount of silica on the various surfaces at the early basic $\mathrm{pH}$ that yield deprotonation of the silica surface hydroxyl groups and therefore a reduction of the H-bond potential. 


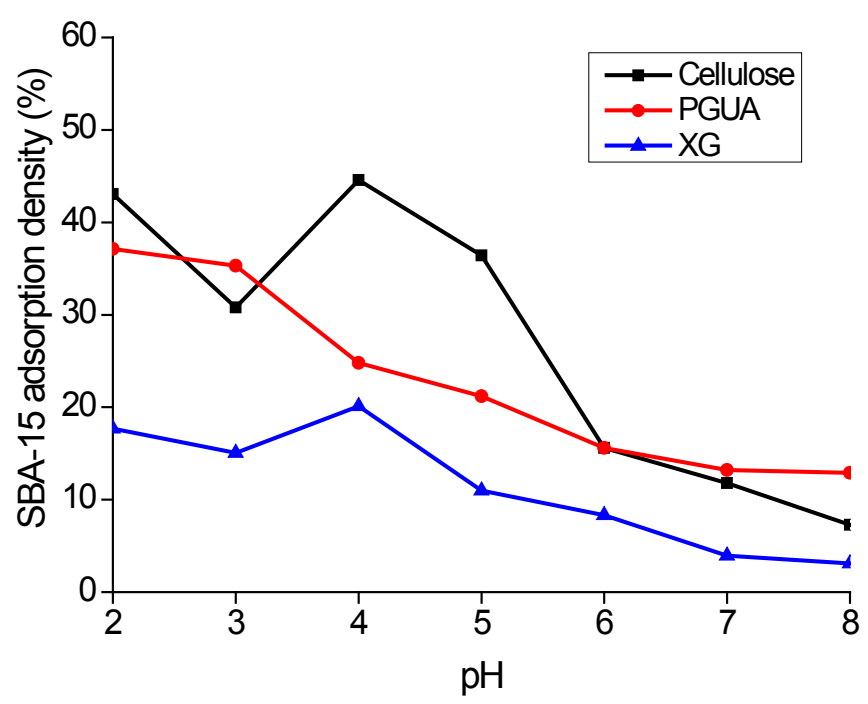

Figure 5. Adsorption of SBA-15 in the various polysaccharides as a function of solution $\mathrm{pH}$.

An interesting result that can be observed from the AFM and SEM images is that at $\mathrm{pH}=2$ and 4, the particles are densely packed and distributed on the film surfaces. This means that the attraction between silica particles and their interactions with polysaccharides surfaces is enhanced close to the $\mathrm{pH}$ of isoelectric point. Indeed Figure 5 shows that for cellulose and $\mathrm{XG}$, the adsorption amounts first increased with $\mathrm{pH}$ increasing to reach a maximum at $\mathrm{pH}=4$ then decreased in basic conditions. This effect is related to the better dispersion of the particles on the surfaces at this $\mathrm{pH}$ but is not fully explained by the balance of the van der Waals versus elec- trostatic forces. Moreover, the adsorption behavior on PGUA decreases continuously with $\mathrm{pH}$ increase. This is presumably due to its strong anionic surface charge density increase with increasing $\mathrm{pH}$ as can be seen in Figure 3 .

\subsection{Effect of Ionic Strength on Silica Adsorption}

To explore the role of electrostatic interactions on adsorption of silica particles at the surface of the different polysaccharides, tests were carried out at $\mathrm{pH} 4$ in the presence of $\mathrm{CaCl}_{2}(0.005 \mathrm{M}$ to $0.05 \mathrm{M})$, using an initial SBA-15 concentration of $1 \mathrm{~g} / \mathrm{L}$.

Adsorption capacities of SBA-15 calculated from SEM images at different salt concentrations are shown in Figure 6. The adsorbed amount increased with increasing the ionic strength following screening-enhanced adsorption regime. The screening effect of the salt reduced the electrostatic repulsions between the polymer chains and the silica particles both negatively charged.

\subsection{Evaluation of Hydrogen Bonding Interactions}

To check the contribution of the hydrogen bonding in the silica particles adsorption behaviour on the polysaccharide films, we have studied this adsorption efficiency in the presence of urea by immersing the polysaccharide surface-coated SBA-15 in a $1 \mathrm{M}$ urea solution. It is known that urea can be used as a strong hydrogen bond breaker [39] [40]; indeed it can be used for disrupting the hydrogen bridges possible to be present between hydroxyl groups of the polysaccharide surfaces and SBA-15 silanol functions. Figure 7 shows the SEM images of the polysaccharide surfaces before and after exposure to urea solution. It is noticed that the adsorption capacity was significantly affected by the presence of urea, showing clearly that area decreases strongly the adsorbed amount of SBA-15 on all the polysaccharide surfaces. This effect is very significant on PGUA for which the adsorption is close to zero in the presence of urea. The surface coverage is also reduced for cellulose whereas only a slight reduction is observed for xyloglucane.

The obtained result emphasizes the important role played by hydrogen bonding in the adhesion of the SBA-15 particles on the polysaccharide films. 


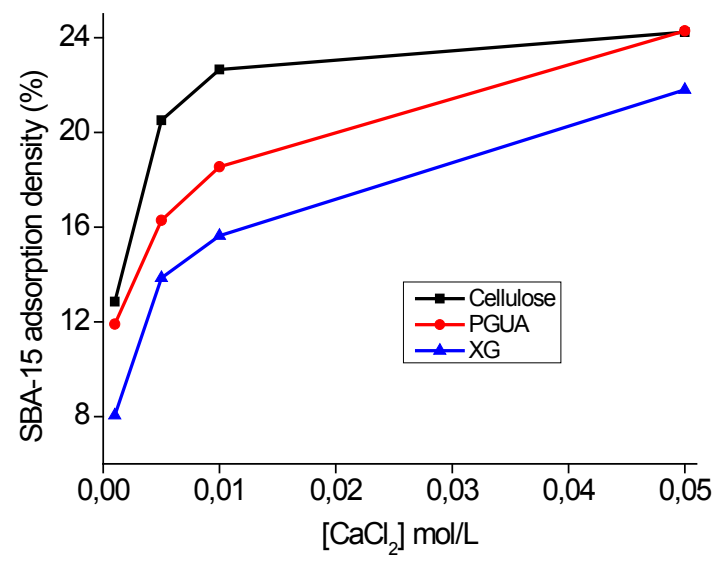

Figure 6. Adsorption of SBA-15 in the various polysaccharides as a function of $\mathrm{CaCl}_{2}$ concentration.
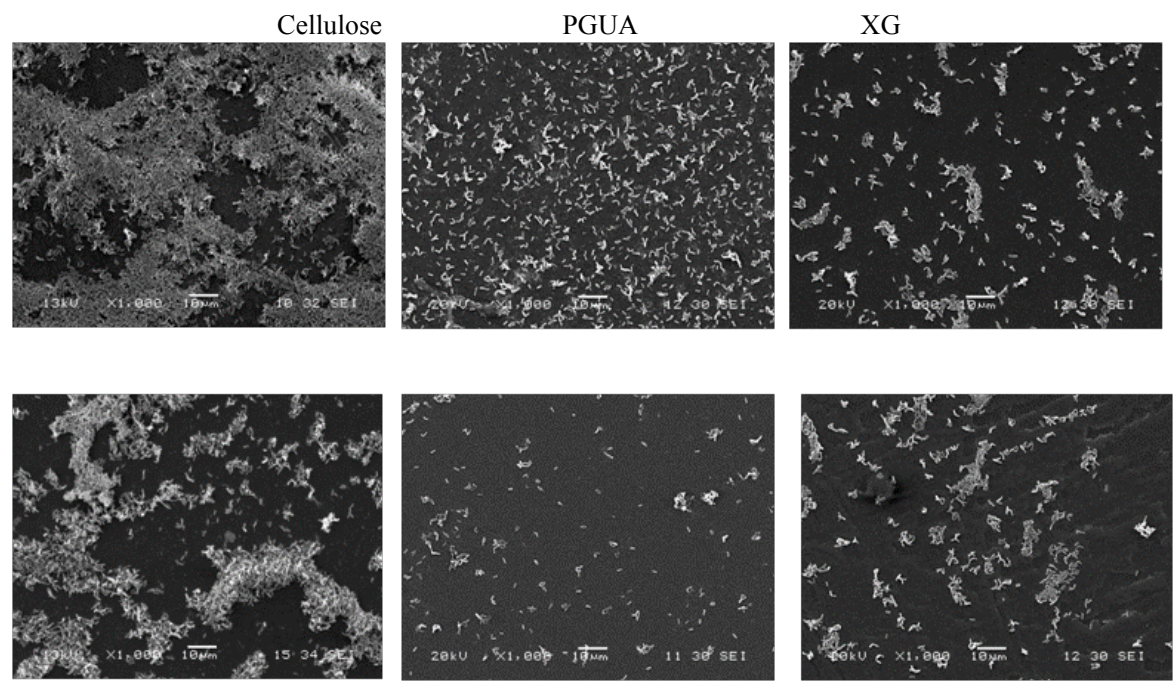

Figure 7. SEM images of SBA-15 adsorbed on the polysaccharide films in the absence (up) and presence (down) of urea. From the left to the right the polysaccharides are Cellulose, Poly Galacturonic Acid (PGUA) and xyloglucane (XG). The upper images represent SBA15 silica particles without urea and the lower images SBA-15 silica with urea.

\subsection{From Polysaccharide Model Surfaces to Real Flax Fibers}

To evaluate the different flax fibers surface treatments on the adsorption of SBA-15 particles, experiments were performed using untreated and three various treated (soxhlet, water, and $\mathrm{NaOH}$ ) bundles of fibers at $\mathrm{pH} 4$. SEM images shown in Figure 8 indicate that surface fiber treatments play a significant role in the adsorption of silica, showing the efficiency of the treatments on the improvement of the interfacial adhesion. The adsorption density was remarkably increased after each treatment. Several reviews in literature are dedicated to the identification of the effect of the different treatments on the surface chemical composition [41]. It was previously reported that soxhlet solvent extraction permit to clean the fibers surface by removing waxy materials and organic impur- ities which induces a surface rich on pectins and hemicelluloses. Water treatment is known to remove pectins to yield hemicelluloses rich fiber surface. Alkali treated fires called mercerization removes pectins and hemicellu- loses revealing highly clean separated fibers with a surface composition dominated by cellulose [42]. this treat- ment is known also to activate the $\mathrm{OH}$ groups of the cellulose [43], it's largely used to improve the mechanical properties of natural fibers used as reinforcement in composite materials [13] [14].

The PGUA, XG and cellulose thin films investigated in this work nicely model these three treatments. SBA15 adsorption on the flax fibers is in excellent agreement with those obtained on polysaccharide model surfaces. 


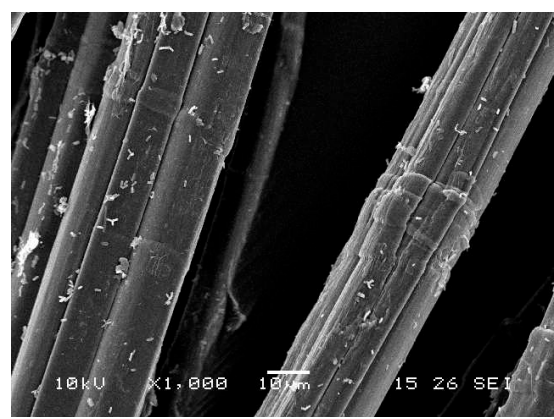

(a)

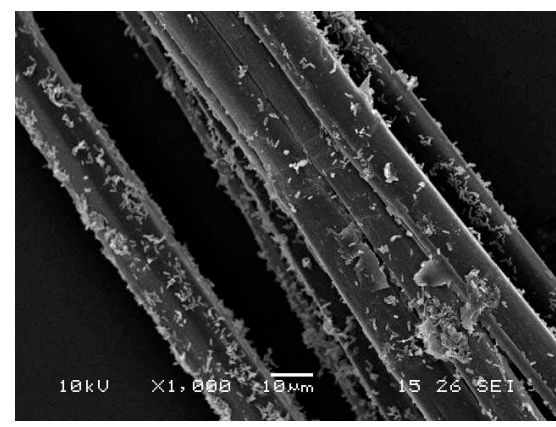

(c)

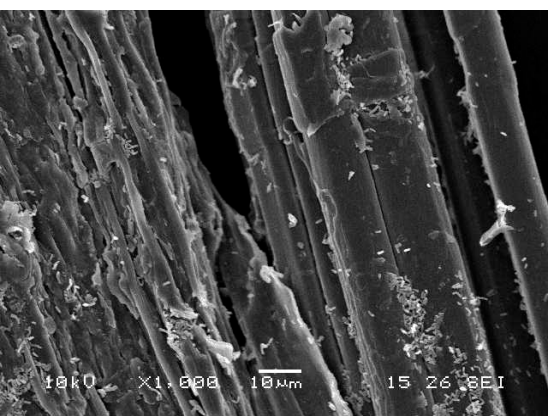

(b)

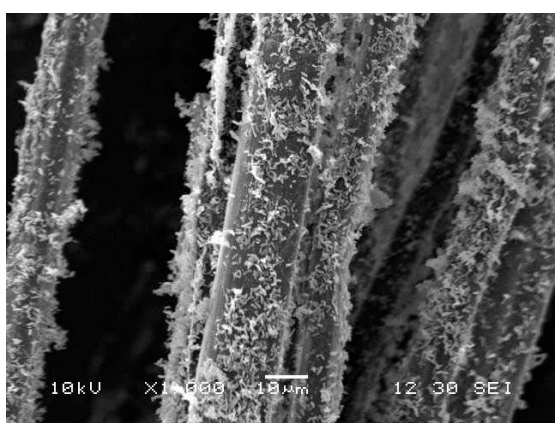

(d)

Figure 8. SEM images of SBA-15 adsorbed on (a) untreated flax fibers and on (b) soxhlet, (c) water, (d) $\mathrm{NaOH}$ treated fibers at $\mathrm{pH} 4$ and a soaking time of $2 \mathrm{~h}$.

Differences on the surface chemical composition of the fibers due to the different treatments are of crucial role in the interfacial adhesion of the SBA-15 with the flax fibers. Indeed, the highest affinity of the two materials is obtained in the case of $\mathrm{NaOH}$-treated fibers known for their cellulose rich surface in good agreement with the results of the adsorption on the model surfaces. The adsorption of SBA 15 ranked from PGUA $<$ XG $<$ Cellulose.

\section{Conclusion}

This study aimed at identifying and understanding the nature of interactions between SBA-15 mesoporous silica particles and flax fibers. Because of the complexity of the flax fibers system, we have studied these interactions independently on the main constituents of the flax fibers representing them by model surfaces, by following the adsorption of the silica particles onto the polysaccharide model surfaces. PGUA and XG surfaces exhibited smooth topography with RMS roughness of $0.7 \mathrm{~nm}$, while cellulose film was rougher with an RMS of $4 \mathrm{~nm}$. All the model surfaces show a hydrophilic character, owing to the strong interaction between the hydroxyl groups of polysaccharides and water molecules. The magnitude of $\xi$-potential values of both silica and polysaccharides increased with increasing $\mathrm{pH}$, whereas they decreased with increasing ionic strength. AFM and SEM results demonstrated that silica adsorption density varied significantly in $\mathrm{pH}$ with the highest at $\mathrm{pH} 4$, while it increased with increasing of the $\mathrm{Ca}^{2+}$ amount. Silica was adsorbed preferentially onto cellulose, followed by PGUA, then XG surfaces. These results support the important role of electrostatic interactions in the adsorption of SBA-15 onto polysaccharide surfaces and the high contribution of hydrogen bonding. Finally, results of adsorption of SBA-15 directly on both raw and treated real flax fibers are consistent with those obtained with model surfaces. SEM images have shown that the $\mathrm{NaOH}$-treatment of the surface fibers improve strongly their adhesion with SBA-15 mesoporous silica particles.

\section{References}

[1] Markus, S., Edgar, R.F.W., Raymond, V. and Thomas, S.J. (2004) Theoretical Studies of High-Temperature Multilayer Thermal Insulations Using Radiation Scaling. Journal of Quantitative Spectroscopy and Radiative Transfer, 84, 477491. http://dx.doi.org/10.1016/S0022-4073(03)00264-4 
[2] Holman, J.P. (2005) Heat Transfer. China Machine Press, Boca Raton.

[3] Zeng, S.Q., Hunt, A. and Greif, R.J. (1995) Theoretical Modeling of Carbon Content to Minimize Heat Transfer in Silica Aerogel. Journal of Non-Cryst Solids, 186, 271-277. http://dx.doi.org/10.1016/0022-3093(95)00076-3

[4] Kennard, E.H. (1938) Kinetic Theory of Gases, with an Introduction to Statistical Mechanics. McGraw-Hill, New York.

[5] Baetensa, R., Jelle, B.P. and Gustavsend, A. (2011) Aerogel Insulation for Building Applications: A State-of-the-Art Review. Energy and Buildings, 43, 761-769. http://dx.doi.org/10.1016/j.enbuild.2010.12.012

[6] Biesmans, G., Randall, D., Français, E. and Perrut, M. (1998) Caracterisation des Proprietes des Aerogels. Proceedings of the 5th International Symposium on Aerogels (ISA 5), 225, 220-225.

[7] Rigacci, A., Marechal, J.C., Repoux, M., Moreno, M. and Achard, P. (2004) Preparation of Polyurethane-Based Aerogels and Xerogels for Thermal Superinsulation. Journal of Non-Crystalline Solids, 350, 372-378. http://dx.doi.org/10.1016/j.jnoncrysol.2004.06.049

[8] Kim, C.-Y., Lee, J.-K. and Kim, B.-I. (2008) Synthesis and Pore Analysis of Aerogel-Glass Fiber Composites by Ambient Drying Method. Colloids and Surfaces A: Physicochemical Engineering Aspects, 313-314, 179-182. http://dx.doi.org/10.1016/j.colsurfa.2007.04.090

[9] Clark, J.H. and Macquarrie, D.J. (2009) Tuneable Porous Carbonaceous Materials from Renewable Resources. Journal of Materials Chemistry, 19, 8512-8514. http://dx.doi.org/10.1039/b920323k

[10] Huijun, W., Jintu, F. and Ning, D. (2007) Thermal Energy Transport within Porous Polymer Materials: Effects of Fiber Characteristics. Journal of Applied Polymer Science, 106, 576-583. http://dx.doi.org/10.1002/app.26603

[11] Morvan, C., Onzighi, C.A., Girault, R., Himmelsbach, D.S., Driouich, A. and Akin, D.E. (2003) Building Flax Fibres: More than One Brick in the Walls. Plant Physiology and Biochemistry, 41, 935-944. http://dx.doi.org/10.1016/j.plaphy.2003.07.001

[12] Charlet, K., Baley, C., Morvan, C., Jernot, J.P., Gomina, M. and Bréard, J. (2007) Characteristics of Hermès Flax Fibres as a Function of Their Location in the Stem and Properties of the Derived Unidirectional Composites. Composites Part A: Applied Science and Manufacturing, 38, 1912-1921. http://dx.doi.org/10.1016/j.compositesa.2007.03.006

[13] Baley, C., Busnel, F., Grohens, Y. and Sire, O. (2006) Influence of Chemical Treatments on Surface Properties and Adhesion of Flaxfibre-Polyester resin. Composites Part A: Applied Science and Manufacturing, 37, 1626-1637. http://dx.doi.org/10.1016/j.compositesa.2005.10.014

[14] Arbelaiz, A., Cantero, G., Fernández, B., Mondragon, I., Gañán, P. and Kenny, J.M. (2005) Flax Fiber Surface Modifications: Effects on Fiber Physico Mechanical and Flax/Polypropylene Interface Properties. Polymer Composites, 26, 324-332. http://dx.doi.org/10.1002/pc.20097

[15] Kymäläinen, H.R. and Sjöberg, A.M. (2008) Flax and Hemp Fibres as Raw Materials for Thermal Insulations. Building and Environment, 43, 1261-1269. http://dx.doi.org/10.1016/j.buildenv.2007.03.006

[16] Kozłowski, R., Mieleniak, B., Muzyczek, M. and Mańkowski, J. (2008) Development of Insulation Composite Based on FR Bast Fibers and Wool. International Conference on Flax and Other Bast Plants, Saskatoon, 21-23 July 2008, 176-182.

[17] El Hajj, N., Mboumba-Mamboundou, B., Dheilly, R.M., Aboura, Z., Benzeggagh, M. and Queneudec, M. (2011) Development of Thermal Insulating and Sound Absorbing Agro-Sourced Materials from Auto Linked Flax-Tows. Industrial Crops and Products, 34, 921-928. http://dx.doi.org/10.1016/j.indcrop.2011.02.012

[18] Innerlohinger, J., Weber, H.K. and Kraft, G. (2006) Aerocell Aerogels from Cellulose Materials. Lenzinger Berichte, 86, $137-143$.

[19] Choi, H.G., Ha, T.J., Yu, B.G., Jaung, S.P., Kwon, O. and Park, H.H. (2008) Improvement of Uncooled Infrared Imaging Detector by Using Mesoporous Silica as a Thermal Isolation Layer. Asian Meeting on Electroceramics, 34, 833836.

[20] Holmberg, M., Wigren, R., Erlandsson, R. and Claesson, P.M. (1997) Interactions between Cellulose and Colloidal Silica in the Presence of Polyelectrolytes. Colloids and Surfaces A: Physicochemical and Engineering Aspects, 129-130, 175-183. http://dx.doi.org/10.1016/S0927-7757(97)00036-8

[21] Hou, A., Shi, Y. and Yu, Y. (2009) Preparation of the Cellulose/Silica Hybrid Containing Cationic Group by Sol-Gel Crosslinking Process and Its Dyeing Properties. Carbohydrate Polymers, 77, 201-205. http://dx.doi.org/10.1016/j.carbpol.2008.12.022

[22] Kalia, S., Dufresne, A., Cherian, B.M., Kaith, B.S., Avérous, L., Njuguna, J. and Nassiopoulos, E. (2011) CelluloseBased Bio- and Nanocomposites: A Review. International Journal of Polymer Science, 2011, Article ID: 837875. http://dx.doi.org/10.1155/2011/837875

[23] Kapsabelis, S. and Prestidge, C.A. (2000) Adsorption of Ethyl(hydroxyethyl)cellulose onto Silica Particles: The Role 
of Surface Chemistry and Temperature. Journal of Colloid and Interface Science, 228, 297-305. http://dx.doi.org/10.1006/jcis.2000.6976

[24] Raj, G., Balnois, E., Baley, C. and Grohens, Y. (2011) Role of Polysaccharides on Mechanical and Adhesion Properties of Flax Fibres in Flax/PLA Biocomposite Role of Polysaccharides on Mechanical and Adhesion Properties of Flax Fibres in Flax/PLA Biocomposite. International Journal of Polymer Science, 2011, Article ID: 503940.

[25] Bendahou, A., Kaddami, H., Sautereau, H., Raihane, M., Erchiqui, F. and Dufresne, A. (2008) Short Palm Tree Fibers Polyolefin Composites: Effect of Filler Content and Coupling Agent on Physical Properties. Macromolecular Materials and Engineering, 293, 140-148. http://dx.doi.org/10.1002/mame.200700315

[26] Kalia, S., Kaith, B.S. and Kaur, I. (2009) Pretreatments of Natural Fibers and Their Application as Reinforcing Material in Polymer Composites: A Review. Polymer Engineering and Science, 49, 1253-1272. http://dx.doi.org/10.1002/pen.21328

[27] Kirby, B.J. and Hasselbrink Jr., E.F. (2004) Theory, Experimental Techniques, and Effects on Separations. Electrophoresis, 25, 187-202. http://dx.doi.org/10.1002/elps.200305754

[28] Nakamura, A., Furuta, H., Kato, M., Maeda, H. and Nagamatsu, Y. (2003) Effect of Soybean Soluble Polysaccharides on the Stability of Milk Protein under Acidic Conditions. Food Hydrocolloids, 17, 333-343. http://dx.doi.org/10.1016/S0268-005X(02)00095-4

[29] Kolasińska, M., Zembala, M., Krasowskaa, M. and Warszyńskia, P. (2008) Probing of Polyelectrolyte Monolayers by Zeta Potential and Wettability Measurements. Journal of Colloid and Interface Science, 326, 301-304. http://dx.doi.org/10.1016/j.jcis.2008.06.053

[30] Obaidat, R., Al-Jbour, N., Al-Sou'd, K., Sweidan, K., Al-Remawi, M. and Badwan, A. (2010) Some Physico-Chemical Properties of Low Molecular Weight Chitosans and Their Relationship to Conformation in Aqueous Solution for Cellulose Chains. Journal of Solution Chemistry, 39, 575-588. http://dx.doi.org/10.1007/s10953-010-9517-x

[31] Carneiro-da-Cunhaa, M.G., Cerqueira, M.A., Souza, B.W.S., Teixeira, J.A. and Vicente, A.A. (2011) Influence of Concentration, Ionic Strength and pH on Zeta Potential and Mean Hydrodynamic Diameter of Edible Polysaccharide Solutions Envisaged for Multinanolayered Films Production. Carbohydrate Polymers, 85, 522-528. http://dx.doi.org/10.1016/j.carbpol.2011.03.001

[32] Mishima, T., Hisamatsu, M., York, W.S., Teranishi, K. and Yamada, T. (1998) Adhesion of $\beta$-D-Glucans to Cellulose. Carbohydrate Research, 308, 389-395. http://dx.doi.org/10.1016/S0008-6215(98)00099-8

[33] Bellmann, C., Caspari, A., Doan, T.T.L. and Mäder, E. (2004) Electrokinetic Properties of Natural Fibres. International Electrokinetics Conference, Pittsburgh, 13-17 June 2004, 245-248.

[34] Bismarck, A., Aranbefwi-Askargorta, I., Springer, J., Lampke, T., Wielage, B., Stamboulis, A., et al. (2002) Surface Characterization of Flax, Hemp and Cellulose Fibers; Surface Properties and the Water Uptake Behavior. Polymer Composites, 23, 872-894. http://dx.doi.org/10.1002/pc.10485

[35] Uetani, K. and Yano, H. (212) Zeta Potential Time Dependence Reveals the Swelling Dynamics of Wood Cellulose Nanofibrils. Langmuir, 28, 818-827. http://dx.doi.org/10.1021/la203404g

[36] Ribitsch, V., Stana-Kleinschek, K., Kreze, T. and Strnad, S. (2001) The Significance of Surface Charge and Structure on the Accessibility of Cellulose Fibres. Macromolecular Materials and Engineering, 286, 648-654. http://dx.doi.org/10.1002/1439-2054(20011001)286:10<648::AID-MAME648>3.0.CO;2-6

[37] Nečesaný, V. (1971) The Isoelectric Point of Lignified Cell Walls. European Journal of Wood and Wood Products, 29, 354-357. http://dx.doi.org/10.1007/BF02621436

[38] Kosmulski, M. and Dekker, M. (2001) Chemical Properties of Material Surfaces.

[39] Zhang, Y., Ghasemzadeh, S., Kotliar, A.M., Kumar, S., Presnell, S. and Williams, L. (1999) Fibers from Soybean Protein and Poly(vinyl alcohol). Journal of Applied Polymer Science, 71, 11-19. http://dx.doi.org/10.1002/(SICI)1097-4628(19990103)71:1<11::AID-APP3>3.0.CO;2-1

[40] Wang, J. and Somasundaran, P. (2005) Adsorption and Conformation of Carboxymethyl Cellulose at Solid-Liquid Interface Using Spectroscopic, AFM and Allied Techniques. Journal of Colloid and Interface Science, 291, 75-83. http://dx.doi.org/10.1016/j.jcis.2005.04.095

[41] Bledzki1, A.K., Mamun, A.A., Lucka-Gabor, A. and Gutowski, V.S. (2008) The Effects of Acetylation on Properties of Flax Fibre and Its Polypropylene Composites. Express Polymer Letters, 2, 413-422. http://dx.doi.org/10.3144/expresspolymlett.2008.50

[42] Raj, G., Balnois, E., Baley, C. and Grohens, Y. (2010) Role of Polysaccharides on Mechanical and Adhesion Properties of Flax Fibres in Flax/PLA Biocomposite. International Journal of Polymer Science, 2011, Article ID: 503940. http://dx.doi.org/10.1155/2011/503940

[43] Wang, B., Panigrahi, S., Tabil, L., Crerar, W. and Sokansanj, S. (2003) Modification of Flax Fibers by Chemical Treatment. CSAE/SVGR Meeting, Montréal, 6-9 July 2003, 88-94. 
Scientific Research Publishing (SCIRP) is one of the largest Open Access journal publishers. It is currently publishing more than 200 open access, online, peer-reviewed journals covering a wide range of academic disciplines. SCIRP serves the worldwide academic communities and contributes to the progress and application of science with its publication.

Other selected journals from SCIRP are listed as below. Submit your manuscript to us via either submit@scirp.org or Online Submission Portal.
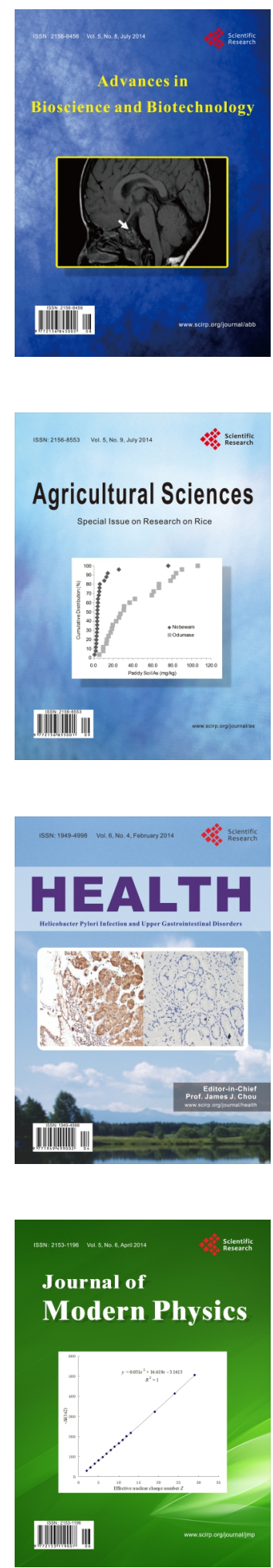
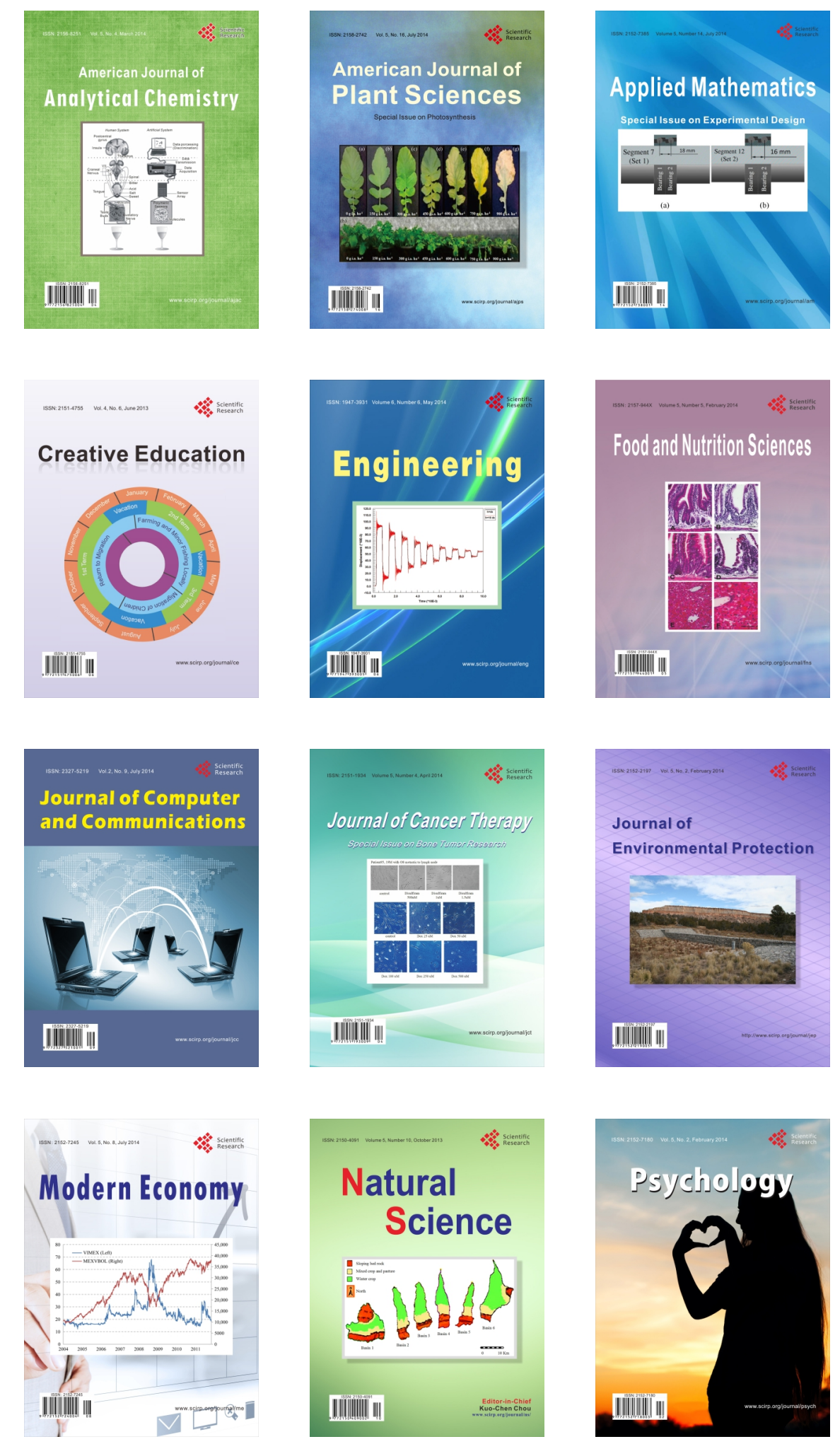